Dmytro Martsenkovskyi, ${ }^{* 1,2}$ Olexandr Napryeyenko, ${ }^{1}$ Igor Martsenkovsky²

\title{
Depression in adolescents exposed to war trauma Risk factors for development of depression in adolescents exposed to war trauma: does PTSD matter?
}

\author{
'Department of Psychiatry, Bogomolets National Medical University, Kyiv, Ukraine \\ 2Department of Mental Disorders in Children and Adolescents, SI 'Institute of Psychiatry of MoH of Ukraine', Kyiv, Ukraine \\ *email: d.martsenkovskyidgmail.com
}

DOI: 10.2478/gp-2020-0018

Received: 26 February 2020; Accepted: 16 June 2020

\begin{abstract}
Background: Depression is frequently comorbid with posttraumatic stress disorder (PTSD) and substantially influences its severity, course and outcomes. Published studies linking war-related paediatric PTSD and Major depressive disorder (MDD) were mainly based on cross-sectional studies.

Objective: To prospectively examine the role of PTSD and other risk/protective factors in the development of depression among adolescents with war-related trauma.

Methods: A longitudinal study of 160 adolescents aged 15-17 years with war-related trauma and displacement due to war in Eastern Ukraine was performed. Of the 160 adolescents, $N=86$ met Diagnostic and Statistical Manual of Mental Disorders, Fourth Edition (DSM-4) criteria for PTSD. All adolescents underwent comprehensive psychiatric assessments that included Kiddie-Schedule for Affective Disorders and Schizophrenia-Present and Lifetime version (K-SADS-PL) administered to both parents and children. Traumatic exposure was assessed using the modified Traumatic Events Screening Inventory for children (TESI-C). PTSD and MDD were assessed with the Clinician-Administered PTSD Scale for Children and Adolescents (CAPS-CA) and Children's Depression Rating Scale-Revised (CDRS-R), and diagnosed using DSM-4 criteria. Follow-up and repeated measurements occurred at 6 and 12 months. During the study, adolescents requiring clinical care were referred for best available care in the community.

Results: Among 92.6\% of study completers, 26/79 youth with PTSD developed MDD (32.9\%), compared to 6/70 without PTSD (8.5\%): relative risk $(R R)=3.83(95 \%$ CI 1.67-8.78), $p=0.0014$; Number needed to harm $(N N T H)=4.108(8.53-2.7)$. Using logistic regression, variables of school attendance, 'secondary' traumatic exposure, and treatment with Trauma-focused Cognitive Behavioral Therapy (TF-CBT) were significantly correlated with the incidence of new-onset depression among adolescents with PTSD.

Conclusions: War-related trauma with subsequent PTSD appears to be a significant risk factor for the later development of depression in adolescents. The role of PTSD as a moderator of depression merits further investigation in larger scale longitudinal studies in diverse populations.
\end{abstract}

\section{Keywords}

Paediatric PTSD, major depressive disorder, war-related trauma

\section{INTRODUCTION}

In 2014, after a period of political instability, anti-Ukrainian military troops occupied the Eastern part of Ukraine. Evacuation of the civil population, especially children, did not start immediately. Military activity began in 2014 and has led to thousands of deaths, resettled populations, destroyed houses, and infrastructure. According to official data, over 1.5 million people were internally displaced (IDPs), with at least 300,000 of them being children and adolescents. Many were directly exposed to war-related events, such as bombardments, rifle fire, living in shelters, death of parents and members of primary support group, and so on (UN Report, 2018).

Posttraumatic stress disorder (PTSD) is one of the most severe psychopathologies that can develop as a response to natural or human-made catastrophic events, including war. When untreated, PTSD can persist throughout life and cause severe 
functional and emotional impairment (Priebe et al., 2009). PTSD is highly comorbid with other mental health pathologies, most commonly with the major depressive disorder. Recent cross-sectional studies of the affected child population showed that up to half of the children and adolescents with PTSD also meet the criteria for a major depressive episode (Adams et al., 2015; Tang et al. 2018; Ayazi et al., 2012).

It is well known that those suffering from PTSD can develop major depressive disorder (MDD) and vice versa. The overlap between the symptoms of both conditions (Flory et al., 2015) can make their diagnosis more complicated. PTSD/MDD comorbidity also influences the severity, course, and outcomes of the illness. A study of adult earthquake survivors found that persons with comorbid PTSD/MDD had significantly higher severity of symptoms and a lower rate of recovery from PTSD (Tural et al., 2012; McLean et al., 2014). Adults with cooccurring PTSD and major depressive episodes had a 2.6 times higher rate of suicidality compared to individuals with PTSD or MDD alone (Ramsawh et al., 2014). Studies of children with PTSD without comorbidities, particularly MDD, documented improved response to psychological treatments (Goldbeck et al., 2016; Jensen et al., 2017; Nanni et al. 2012; Mannarino et al., 2012).

Despite the growing body of research on outcomes of psychological trauma in children, the majority of studies are focused on the cross-sectional prevalence of PTSD, depression, and/or their comorbidity (Perkins et al., 2018; Cenat et al., 2015, Kar et al., 2006; Attanayake et al., 2009; Tang et al. 2018). Majority of studies assess the outcomes of non-war-related trauma (Lai et al., 2013; Valdez et al., 2014; Cheng et al., 2018). Few studies focused on the nature of the relationship between PTSD and MDD (Thabet et al., 2004; Ayazi et al., 2012; Adams et al., 2015; Pejuskovic et al., 2020).

The extreme level of violence is a hallmark of war-related trauma. Studies of Sudanese refugees found that children who were exposed to violent attacks and were injured demonstrated a higher rate of post-traumatic stress disorder (Geltman et al, 2005). Overall, war-related trauma is associated with a higher number of exposed individuals, a higher number of traumatic events, and their greater severity. The study comparing the evacuated youth after Hurricane Katrina with war refugees from Africa and Syria found that war refugees, besides the higher severity of internalizing symptoms, also reported more cases of separation with family and of witnessing more members of a primary support group or strangers injured or killed (Myles et al., 2018).
Besides the lack of data from longitudinal studies on the comorbidity of war-related PTSD and MDD in children, there is also a lack of studies of war-related PTSD and MDD in children from Europe. Most of the published studies of waraffected children have so far assessed children and refugees from Muslim or African countries with unique cultural and religious features.

In the study of war refugees from Africa and Syria who were evacuated to Berlin, these children demonstrated a higher level of distress associated with relocation that was associated with language acquisition and the adaptation to a new culture (Myles et al., 2018). In other instances, refugees have been distressed by racial discrimination and complex legal immigration processes (Fazel et al., 2012).

Several studies outside of Europe found religious coping (such as praying) by youth as the most helpful and frequent coping strategy to alleviate stress and improve stress-related outcomes (Zukerman et al., 2014; Volkl-Kernstock et al., 2014). According to the latest data from sociological studies, only $55 \%$ of inhabitants in Eastern Ukraine consider themselves to belong to an organized religion (Razumkov Center, 2016) - a much lower percentage compared to Muslim or African countries.

Overall, there is a clear need for prospective investigations of war-related PTSD and its comorbidity with MDD in diverse cultural settings.

In this study, we aimed to explore the effects of PTSD on development of depression. The primary goal was to estimate the effect of PTSD on the further onset of depression in youth with war trauma. Secondary goals were to identify potential risk and protective factors for development of depression in adolescents with war trauma. We hypothesized that adolescents with war-related PTSD will have a higher incidence of depression compared to adolescents with war-related trauma, but without PTSD. We also hypothesized that adolescents with PTSD will be more vulnerable to post-displacement traumatic events compared to their peers without PTSD.

\section{METHOD}

\section{Procedure}

This study was approved by the Committee of Ethics in Bogomolets National Medical University. Detailed information about the study was provided to the adolescents and their legal guardians and written informed consent was obtained before study entry. 
The sample size calculation estimated that total number of 102 adolescents (51 per group) was required to achieve $80 \%$ power at 0.05 type I error rate to detect the difference in prevalence of MDD among PTSD and non-PTSD adolescents. These calculations were based on the literature average cross-sectional $40 \%$ prevalence of depression after traumatic events among children with PTSD (Lai et al., 2013; Kar et al., 2006; Tang et al., 2018) and 15\% among children without PTSD (Salloum et al., 2018; Karam et al., 2014; Tang et al., 2018). Taking into account a possible 25 to $30 \%$ attrition during the follow-up period, we set a minimum number of 70 adolescents per study group.

Sample recruitment was done from May 2014 to April 2016 through social service agencies working with war-exposed internally displaced persons (IDPs). No specific incentives were used for study recruitment. We used stratified sampling to reach 483 adolescents 15-17 years old. Among them, 216 (44.7\%) child/parent dyads responded to the proposal to participate in the study. The final patient assessment was conducted in April, 2017.

Before inclusion in the study, adolescents were assessed for eligibility using a 2-step ascertainment. Initially, we ascertained the presence of exposure to war-related traumatic events, history of past psychological trauma, and whether the child met A criterion DSM-4 for PTSD: '(1) Person experienced, witnessed, or was confronted with an event or events that involved actual or threatened death or serious injury, or a threat to the physical integrity of self or others; (2) The person's response involved intense fear, helplessness, horror, disorganized or agitated behavior.' (American Psychiatric Association, 2000).

This information was gathered by 6 social workers specially trained to use a modified version of TESI-C. Subsequently, the children were evaluated for both current and lifespan presence of mental health problems by two child and adolescent psychiatrists experienced in working with children with psychological trauma. The types, number of traumatic exposures, and presence of mental health symptoms were ascertained from adolescents and their caregivers. Presence of serious non-psychiatric disorders was obtained from the available medical records and from parents.

Exclusion criteria were as follows: lack of exposure to warrelated traumatic events, presence of a previous non-war-related psychological trauma, presence of any mental health disorders at the time of evaluation, except Posttraumatic Stress Disorder (PTSD), or past diagnosis of any neurological, psychiatric, or serious chronic physical illness.
After enrolment and evaluation (T0), all children were involved in a 12 months period of observation with a follow-up assessment at 6 months (T1) and at the 12 months study endpoint (T2). At all time points, the presence of depression and its severity and prevalence of secondary traumatic events were assessed. The events were classified as secondary traumatic if they happened after or were associated with displacement and caused severe feelings of hopelessness or social withdrawal. During the study, children requiring clinical care were referred for the best available care in the community and had no limitations in their treatment options. We also assessed the severity of PTSD at the beginning (T0) and the study endpoint (T2).

\section{Participants}

The final sample included 160 adolescents and consisted of 75 (46.9\%) females and 85 (53.1\%) males. Selected participants were on average 15.87 ( $\mathrm{SD}=0.77$ ) years old. All children were white, 119 (74.4\%) indicated that they were Ukrainians and 41 (25.6\%) Russians. Among them, 97 (60.6\%) were high school students, 63 (39.4\%) were studying in vocational schools. This pattern was equally distributed in both cohorts. The recruited sample was presented by a child/parent dyad, all children were living with the families of origin.

All randomized adolescents met DSM-4 A criteria for PTSD. About half, or 86 of them also met full DSM-4 criteria for PTSD. Most of the adolescents have experienced multiple warrelated traumatic events, (median $=2$, range $=1-5$, interquartile range $=2-3$ ) and were assessed at least 3 months (median $=$ 8 months, range $=4-11$ months, interquartile range $=6-9$ months) after the first traumatic event occurred. Among those involved in the study, $59(36.8 \%)$ adolescents had houses damaged during the war, 101 (63.1\%) experienced living in shelters with a lack of access to food and clean water, while 53 (33.1\%) experienced direct bombardments. Over a third, $58(36.2 \%)$ of the participants heard rifle fire, and 86 (53.7\%) witnessed dead bodies of their neighbours and familiar people. Twelve (7.5\%) of the adolescents were physically injured during the war, and 29 (18.1\%) had a member from a primary support group injured. Most of the adolescents were re-located with their parents, however, $63(39.3 \%)$ of them had one of the parents stay in military zone. Socio-demographic data of the sample and characteristics of traumatic exposure are presented in Table 1.

\section{Measures}

1. The traumatic Events Screening Inventory for children (TESI-C) (Ribbe et al., 1996). This questionnaire consists of 
Table 1. Socio-demographic data and characteristics of traumatic exposure of adolescents enrolled in the study

\begin{tabular}{|c|c|c|c|}
\hline \multirow{2}{*}{ Variable } & \multicolumn{2}{|c|}{ M (SD)/ Median (IQR)/ $\mathbf{n}(\%)$} & \multirow{2}{*}{ P value } \\
\cline { 2 - 4 } & PTSD & Non-PTSD & $>.05$ \\
\hline Age lyears) & $15.87(0.77)$ & $15.86(0.76)$ & $>.05$ \\
\hline Female gender & $38(48.1 \%)$ & $8.0(6.0-9.0)$ & $>.05$ \\
\hline Time since trauma, months & $8.0(6.0-9.0)$ & $2.0(1.0-3.0)$ & $>.05$ \\
\hline $\begin{array}{c}\text { Number of traumatic events } \\
\text { exposed }\end{array}$ & $3.0(2.0-4.0)$ & & $>.05$ \\
\hline $\begin{array}{c}\text { Characteristics of war- } \\
\text { exposure: }\end{array}$ & & $20(28.5 \%)$ & $>.05$ \\
\hline - bombardments & $27(34.1 \%)$ & $24(30.3 \%)$ & $>.05$ \\
\hline - rifle fire & $30(37.9 \%)$ & $5(7.1 \%)$ & $>.05$ \\
\hline - injured & $7(8.8 \%)$ & $12(17.1 \%)$ & $>.05$ \\
\hline - parents injured & $17(21.5 \%)$ & $36(51.4 \%)$ & $>.05$ \\
\hline - saw dead bodies & $48(60.7 \%)$ & $45(64.2 \%)$ & $>.05$ \\
\hline - living in shelters & $52(65.8 \%)$ & $25(35.7 \%)$ & \\
\hline - house damaged & $30(37.9 \%)$ & & \\
\hline
\end{tabular}

19 questions that explore the most prevalent traumatic events in childhood and assess child's appraisal. The instrument allows to assess whether the endorsed events meet DSM-4TR A criterion for PTSD. This instrument was translated into Ukrainian and then back-translated to ensure validity.

For our study needs, we expanded the instrument by adding 8 questions devoted to war-related traumatic events. They included 'being under bombardments, being under rifle fire, hiding in shelters, starving, had a house destroyed, being injured due to war actions, saw somebody being killed or wounded seriously, had a close relative killed or seriously injured.' The added questions had the same structure as original and also assessed the subjective appraisal of the event by a child. The information about possible traumatic exposure was obtained from both adolescents and their parents.

2. The Kiddie-Schedule for Affective Disorders and Schizophrenia-Present and Lifetime version (K-SADS-PL) (Kaufman et al., 1997). We used the version based on DSM4 -TR criteria in the study. This semi-structured interview is a widely used instrument that evaluates all major childhood psychiatric disorders including PTSD. This instrument was administered to all adolescents who met A-criteria for PTSD and their parents by a psychiatrist trained to use structured interview techniques of K-SADS-PL. In combination with semi-structured interview results, DSM-4-TR criteria were used for confirmation of PTSD diagnosis. K-SADS-PL was administered to both children and their parents. The interviews with children and their parents were conducted in Ukrainian/
Russian languages. During the assessment, the English version of the semi-structured interview was used by the Ukrainian specialists fluent in English/Ukrainian/Russian languages.

The Anxiety, Obsessive-compulsive, and Trauma-related supplements of the K-SADS-PL were administered to all participants enrolled in the study. Only adolescents who met full DSM-4-TR criteria were considered as having PTSD.

3. Clinician-Administered PTSD Scale for Children and Adolescents (CAPS-CA) (Nader et al., 1996) based on adult gold standard assessment for PTSD (Blake et al., 1995) was administered to assess the severity of posttraumatic symptoms according to DSM-4-TR criteria. This instrument assesses the frequency and intensity of the 17 symptoms of PTSD across re-experiencing, hyperarousal, avoidance, and numbing subdomains. Children who did not meet full criteria for PTSD on K-SADS-PL, but had more than 30 points on CAPS-CA and had a severe functional impairment as a result of posttraumatic symptoms that could not be explained by other mental health problems were diagnosed with PTSD. Those with only some PTSD symptoms were regarded as non-PTSD. CAPS-CA was conducted only with adolescents, and not with parents. The CAPS-CA demonstrated good internal consistency in the study $(\alpha=0.81-0.87)$. The interviews with children were conducted in Ukrainian/Russian languages by Ukrainian specialists. During the assessment, the English version of the semi-structured interview was used by the Ukrainian specialists fluent in English/Ukrainian/Russian languages. 
4. The Children's Depression Rating Scale-Revised (CDRS-R) (Poznanski and Mokros, 1996). The version of the scale based on DSM-4-TR criteria was used in the study. This semi-structured rating scale is one of the most widely used instruments for the clinical rating of depression in children and adolescents. This instrument was administered to all adolescents during T0, Tl, and T2 study time-points. Adolescents were regarded as screenpositive for depression if they had more than $45 \mathrm{~T}$-Score points on CDRS-R. The CDRS-R internal consistency in this study was high $(\alpha=0.89)$. CDRS-R screening was conducted with the children only by a Ukrainian specialist fluent in English/ Ukrainian/Russian languages and experienced in using the scale. English version of the scale was used throughout the study.

The presence of depression was further confirmed by a depressive and bipolar related disorder supplement of K-SADSPL and DSM-4-TR criteria in all positive CDRS-R screened adolescents. During the follow-up observations, children were not assessed for any other psychopathologies except for depression.

\section{Data Analysis}

Statistical analysis was performed using the Statistical Package for Social Sciences (SPSS, version 21.0). Descriptive statistics were provided as mean (SD) and frequency (\%) as appropriate. Before the analysis, discrete data received through assessments was dichotomized.

All dummy variables were coded as '1' for 'yes' and ' 0 ' for 'no'. For statistical needs, all post-displacement traumatic events were unified in a «secondary traumatic events» category, coded as «l» if the child had at least one of them through the year. School non-attending was coded as «1» if adolescents missed $50 \%$ and more of classes during the year. TF-CBT and fluoxetine were coded as «1» if adolescents had this treatment throughout the year before being diagnosed with an episode of depression. If these treatments were received after the initial diagnosis of depression, for statistical purposes, they were coded as «0».

To compare groups, chi-square tests were used for categorical data and T-tests or Mann-Whitney $\mathrm{U}$ for continuous variables as appropriate. Analysis of contingency tables was used to estimate the differences in the number of depression cases between adolescents with and without PTSD.

Post-hoc binary logistic regression analysis in all the included adolescents and separately in those adolescents with PTSD was used to examine the association of depression with PTSD and

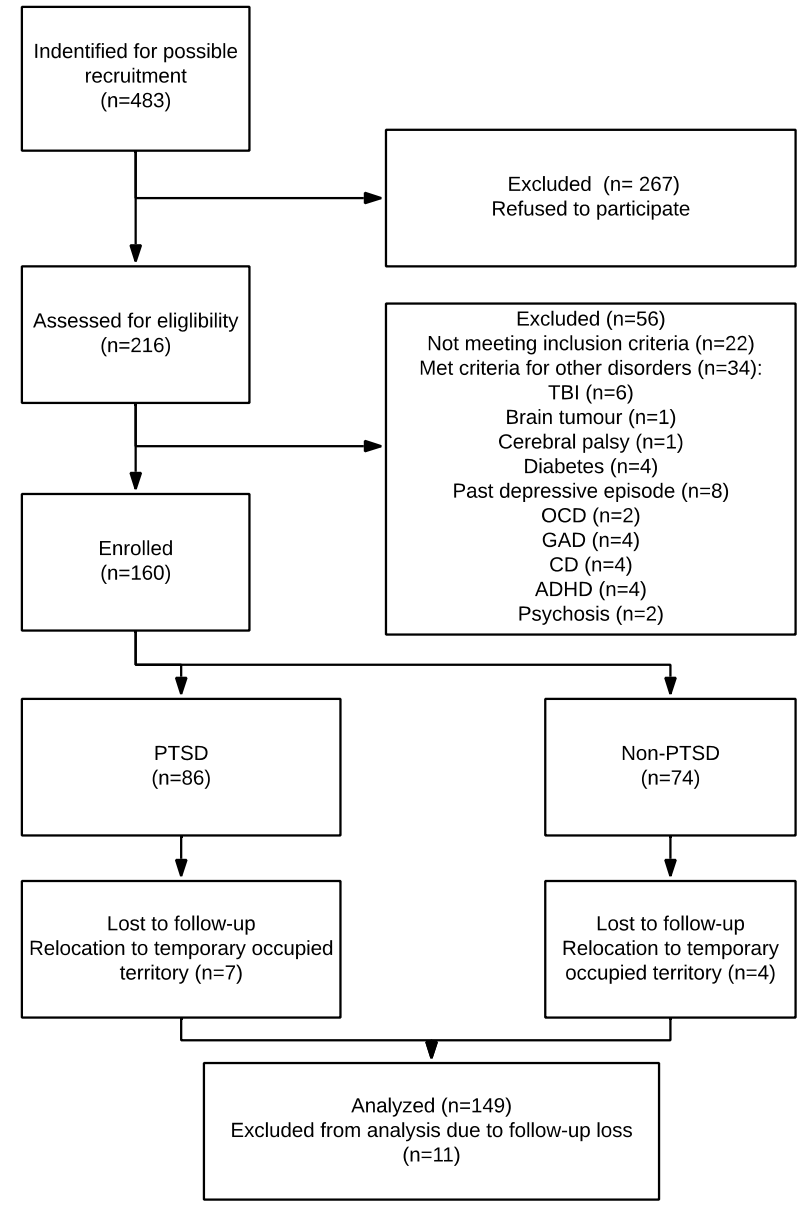

Figure 1. CONSORT diagram. TBI - traumatic brain injury; OCD obsessive-compulsive disorder; GAD - generalized anxiety disorder; CD - conduct disorder; ADHD - attention deficit/hyperactivity disorder; PTSD - posttraumatic stress disorder

other co-variables. The effects of the predictors were given as $P$-values and odds ratios with $95 \%$ confidence intervals (upper, lower).

Repeated measures ANOVA with Bonferroni correction were used to estimate the difference in severity of PTSD and MDD at different time points.

\section{RESULTS}

Over the course of the year-long observation, 11 adolescents were lost to follow-up due to their relocation back to the occupied territory. The loss to follow-up was 11 out of 160, or well below 10\%. A Consort Flowchart for the study is presented in a Figure 1. 
Table 2. Description of mental health care provided in the community to adolescents with PTSD involved in the study

\begin{tabular}{|c|c|}
\hline Variable & $\%$ \\
\hline Received TF-CBT & $32,9 \%$ \\
\hline Received Fluoxetine & $20,25 \%$ \\
\hline Being hospitalized & $6,3 \%$ \\
\hline Received regular care & $46,8 \%$ \\
\hline
\end{tabular}

Note. TF-CBT = trauma-focused cognitive-behavioral therapy; regular care - receiving TF-CBT or Fluoxetine under regular supervision throughout the study.

Table 3. Characteristics of post-displacement traumatic exposure of adolescents at study endpoint (T2)

\begin{tabular}{|c|c|c|c|}
\hline \multirow{2}{*}{ Variable } & \multicolumn{2}{|c|}{$\begin{array}{c}\text { M (SD)/ Median (IQR)/ } \\
\mathbf{n}(\%)\end{array}$} & \multirow{2}{*}{ P value } \\
\cline { 2 - 3 } & PTSD & Non-PTSD & \\
\hline $\begin{array}{c}\text { Number of post- } \\
\text { displacement traumatic } \\
\text { events exposed }\end{array}$ & $0.0(0.0-1.0)$ & $0.0(0.0-1.0)$ & $>.05$ \\
\hline $\begin{array}{c}\text { Characteristics of post- } \\
\text { displacement: }\end{array}$ & $15(18.9 \%)$ & $10(14.2 \%)$ & $>.05$ \\
\hline $\begin{array}{c}\text { - bullying } \\
\text { status }\end{array}$ & $18(22.7 \%)$ & $13(18.5 \%)$ & $>.05$ \\
\hline $\begin{array}{c}\text { - loss of financial/social } \\
\text { - parents divorced }\end{array}$ & $7(8.8 \%)$ & $4(5.7 \%)$ & $>.05$ \\
\hline - parent lost job & $11(13.9 \%)$ & $8(11.4 \%)$ & $>.05$ \\
\hline - grandparent died & $1(1.2 \%)$ & $1(1.4 \%)$ & $>.05$ \\
\hline
\end{tabular}

Among those who completed the study, 26/79 youth with PTSD developed a depressive disorder (32.9\%), compared to 6/70 without PTSD (8.5\%): RR = 3.83 (95\% CI 1.67-8.78), p = 0.0014 ; NNTH $=4.108$ (8.53-2.7). Throughout the year, none of the adolescents involved in the study developed new-onset PTSD.

During the study, 36 (24.1\%) had a non-suicidal self-harming behaviour, 27 (18.1\%) had suicidal thoughts. Among them, 5 (3.3\%) adolescents with PTSD and comorbid depression were hospitalized due to suicidal planning and high suicidal risk. Among adolescents with comorbid PTSD and depression, there were 3 patients with psychotic symptoms that improved with SSRI treatment and were considered to represent psychotic features of depression. Information about mental health care received by adolescents with PTSD in the community is presented in Table 2.
Throughout the year of observation, both cohorts were exposed to multiple post-displacement life events that were regarded as traumatizing. Among those who completed the study, 25 (16\%) were exposed to bullying, 31 (20\%) complained regarding loss of financial/social status, 11 (7\%) had parents divorced, $19(12 \%)$ had a parent being fired at and $2(1 \%)$ had lost their grandparents. Information about types of post-displacement traumatic events is presented in Table 3.

All adolescents were characterized by low school attendance. Adolescents with PTSD were also characterized by low access to psychological and psychiatric care. For example, only 26 of the 79 adolescents with PTSD received Trauma-focused cognitive-behavioural therapy (TF-CBT) during the period of observation.

Before completing the analysis, we examined the demographic differences between the exposed and control groups. No differences were found in adolescents' gender, age, and the time since trauma $(p>0.05)$. In spite of the apparent difference in the number of war-related traumatic events (3.0 [2.0-4.0] in PTSD group and 2.0 [1.0-3.0] in the non-PTSD group), it was not statistically significant $(p>0.05)$. Adolescents in the PTSD group showed a higher level of school non-attending, $\chi^{2}$ (1) = 5.294, $\mathrm{p}<0.05$. Children in both PTSD and non PTSD group were equally exposed to post-displacement traumatic events, $\chi^{2}(1)=1.138, \mathrm{p}=0.286$.

Adolescents in the PTSD group ( $\mathrm{Mdn}=32.0)$ compared to the non-PTSD group ( $\mathrm{Mdn}=27.0$ ) had a higher baseline (T0) severity of depression scores, $\mathrm{U}=953.0, \mathrm{p}<0.001$.

The association between estimated co-variables and depression was analysed using binary logistic regression. Results of the regression are presented in Table 4.

We analysed the possible risk factors for the development of depression and found that having PTSD combined with being a female and non-attending school on a regular basis were significant factors that increased the risk of the onset of depression in adolescents with war-related traumatic exposure. Considering that more than $80 \%$ of all depression cases were in the PTSD cohort, we also analysed it separately.

The post-hoc logistic analysis estimated that secondary traumatic events and school non-attending were correlated with increased risk for comorbid depression in adolescents with PTSD, while treatment with TF-CBT decreased this risk. Results of the regression are presented in Table 5. 
Table 4. Results of logistic regression predicting onset of depression in children exposed to war-related traumatic events

\begin{tabular}{|c|c|c|c|c|c|}
\hline \multirow{2}{*}{ Risk factor } & \multicolumn{4}{|c|}{ Final model } & \multicolumn{2}{|c|}{ OR } & $\mathbf{9 5 \%} \mathbf{C l}$ \\
\cline { 2 - 6 } & B & SE & W & $2.85^{*}$ & $1.06-7.62$ \\
\hline Female gender & 1.049 & .501 & 4.378 & $4.33^{* *}$ & $1.48-12.64$ \\
\hline PTSD & 1.466 & .547 & 7.182 & 1.73 & $.65-4.6$ \\
\hline Secondary trauma $^{a}$ & .548 & .499 & 1.208 & $10.3^{* * *}$ & $3.76-28.2$ \\
\hline School non-attending $^{a}$ & 2.334 & .515 & 20.557 & & \\
\hline
\end{tabular}

Note. $\mathrm{R}^{2}=0.422$ (Nagelkerke); Model $\mathrm{x}^{2}=47.4 ; \mathrm{W}=$ Wald statistic; $\mathrm{OR}=$ odds ratio; $\mathrm{Cl}=$ confidence interval; $\mathrm{PTSD}=$ posttraumatic stress disorder; ${ }^{\text {a }}$ - in a period from T0 to T2.

${ }^{*} \mathrm{p}<.05 ;{ }^{* *} \mathrm{p}<.01 ;{ }^{* * *} \mathrm{p}<.001$.

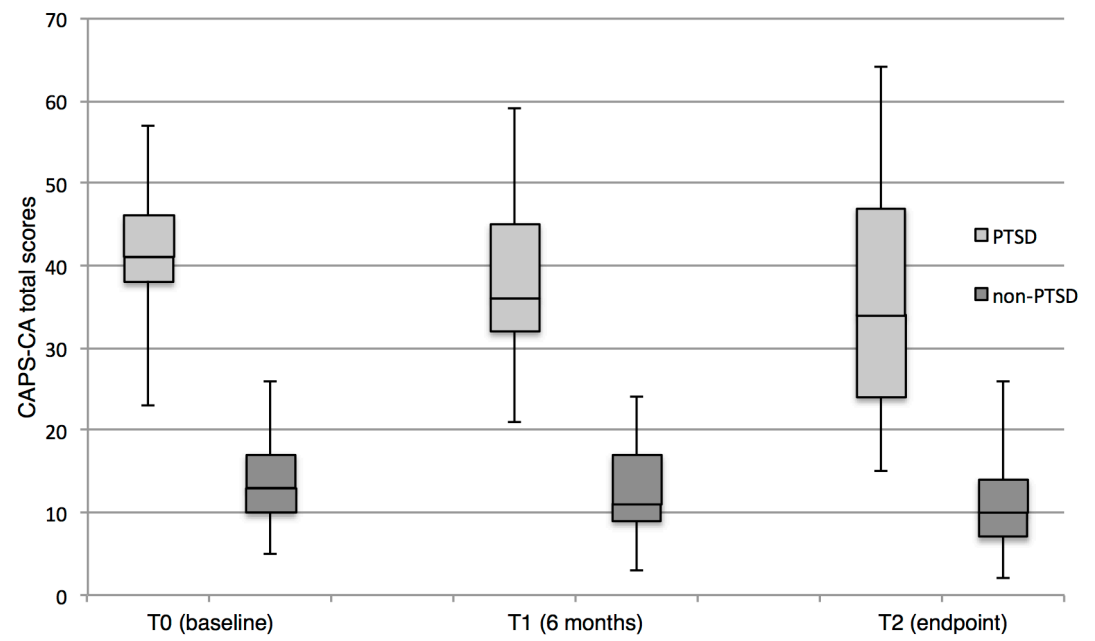

Figure 2. Changes in severity of PTSD on CAPS-CA in adolescents enrolled in the year long study

Note. PTSD -posttraumatic stress disorder; CAPS-CA - Clinician-administered ptsd scale child/adolescent version

Throughout the year-long observation, adolescents in a PTSD group enrolled in the study demonstrated a significant decline in severity of PTSD symptoms on CAPS-CA. Changes in severity of CAPS-CA scores in both PTSD and non-PTSD groups are presented in Figure 2.

The results of repeated measures ANOVA determined that CAPS-CA severity in PTSD group differed statistically significantly between the time points, Wilks' Lambda $=0.782$, $\mathrm{F}(2,77)=10.708, \mathrm{p}=0.001$. Post-hoc tests using the Bonferroni correction revealed that CAPS-CA severity significantly declined from $\mathrm{T} 0$ to $\mathrm{T} 1$ assessments $(41.25 \pm 6.54$ vs $38.6 \pm 8.45$, $\mathrm{p}=0.001)$. CAPS-CA severity at T2 assessment demonstrated further decline up to $35.4 \pm 12.91$, and it was statistically significantly different relative to $\mathrm{T} 0(\mathrm{p}=0.001)$ and $\mathrm{T} 1$ assessments $(\mathrm{p}=0.001)$. The corrected $\mathrm{p}$-threshold was 0.016 .
Despite the decrease in PTSD symptoms, the severity of depressive symptoms on CDRS-R demonstrated an upward trend, in particular due to the increase in severity of depression among patients who did not demonstrate improvement in PTSD severity. Changes in severity of CDRS-R scores in both PTSD and non-PTSD groups are presented in Figure 3.

A Mann-Whitney test indicated that the severity of depressive symptoms on CDRS-R in T1 point was higher in the PTSD group $(\mathrm{Mdn}=34.0)$ than in the non-PTSD group of children $(\mathrm{Mdn}=21.0), \mathrm{U}=6.5, \mathrm{p}<0.001$.

The results of Mann-Whitney test indicated that the severity of depressive symptoms on CDRS- $\mathrm{R}$ in T2 point was higher in the PTSD group ( $\mathrm{Mdn}=34.0)$ than in the non-PTSD group of children $(\mathrm{Mdn}=24.0), \mathrm{U}=103.5, \mathrm{p}<0.001$. 


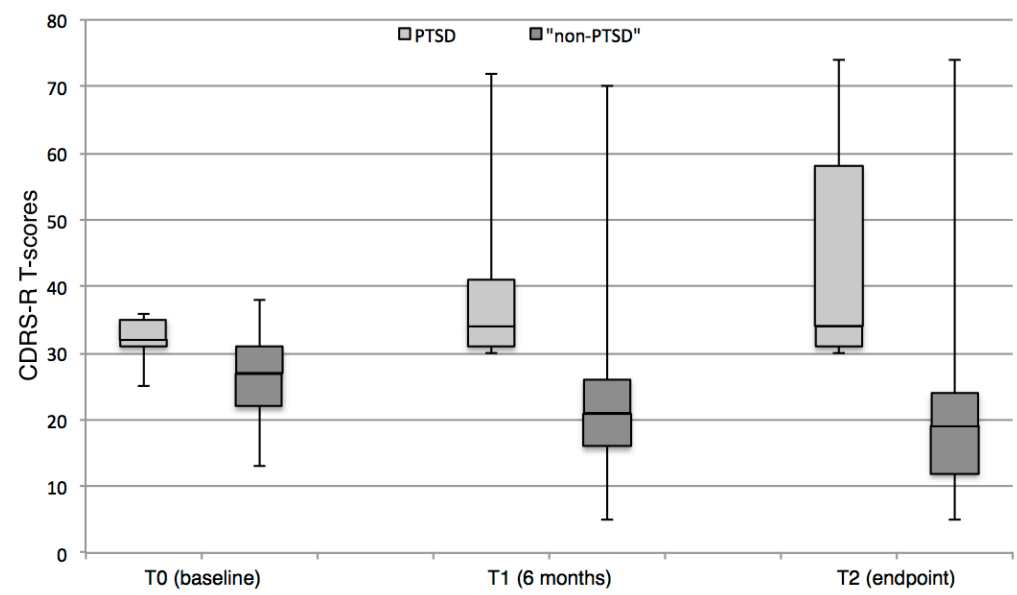

Figure 3. Changes in depression severity on CDRS-R in adolescents enrolled in the year long study Note. CDRS-R - Children's depression rating scale-revised

Table 5. Risk and protective factors for development of depression in adolescents with war-related PTSD

\begin{tabular}{|c|c|c|c|c|c|}
\hline \multirow{2}{*}{ Risk/Protective factor } & \multicolumn{5}{|c|}{ Final model } \\
\cline { 2 - 6 } & B & SE & W & OR & $\mathbf{9 5 \%} \mathbf{C l}$ \\
\hline Female gender & .382 & .744 & .263 & 1.46 & $.34-6.3$ \\
\hline Secondary trauma $^{\mathrm{a}}$ & 1.895 & .718 & 6.963 & $6.65^{* *}$ & $1.62-27.1$ \\
\hline School non-attending $^{\mathrm{a}}$ & 2.485 & .708 & 12.329 & $12.0^{* * *}$ & $2.99-48.0$ \\
\hline TF-CBT & -2.856 & 1.034 & 7.625 & $.058^{* *}$ & $.008-.437$ \\
\hline Fluoxetine & .714 & .859 & .691 & 2.04 & $.37-10.98$ \\
\hline
\end{tabular}

Note. $\mathrm{R}^{2}=0.605$ (Nagelkerke); Model $\mathrm{x}^{2}=55.0 ; \mathrm{W}=$ Wald statistic; $\mathrm{OR}=$ odds ratio; $\mathrm{Cl}=$ confidence interval; $\mathrm{TF}-\mathrm{CBT}=$ trauma-focused cognitive-behavioral therapy; ${ }^{\text {a }}$ - in a period from T0 to T2.

${ }^{*} p<.05 ; * * p .01 ; * * * p<.001$.

The results of repeated measures ANOVA determined that CDRS-R severity in PTSD group differed statistically significantly between the time points, Wilks' Lambda $=0.703$, $\mathrm{F}(2,77)=16.245, \mathrm{p}=0.001$. Post-hoc tests using the Bonferroni correction revealed that CDRS-R severity significantly increased from $\mathrm{T} 0$ to $\mathrm{T} 1$ assessments $(32.6 \pm 2.34$ vs $39.2 \pm 12.03$, $\mathrm{p}=0.001)$. CDRS-R severity at T3 assessment increased to 42.17 \pm 14.84 , that was statistically significantly different relative to $\mathrm{T} 0(\mathrm{p}=0.001)$ and T2 assessments $(\mathrm{p}=0.002)$. The corrected p-threshold was equal to 0.016 .

\section{DISCUSSION}

This study sought to examine the direct and moderating effects of PTSD and other risk factors on the development of depression in a sample of war-exposed adolescents. To our knowledge, this is the first study assessing the effects of war-related PTSD on adolescents in Ukraine. Due to the limited resources and high prevalence of stigma, the majority of adolescents were deprived of both early interventions and subsequent highly specialized trauma-focused treatment. As a result, this study reflects the onset of MDD among adolescents with PTSD as its natural course. That is particularly valuable because most military actions occur in low and middle-income countries with limited access to resources.

In our study, the prevalence of depression among warexposed adolescents was about $20 \%$ and was consistent with the published literature (Kien et al., 2019). However, due to the methodological features, particularly the exclusion of adolescents with any psychiatric disorders except for PTSD from this study, it likely underestimates the actual prevalence of depression among the affected adolescents in the general population. 
The above exclusion may help explain the lower estimated comorbidity rate of PTSD and depression when compared to the recent studies in children and adolescents (Lai et al., 2013; Adams et al., 2015; Tang et al., 2018), with published rates of comorbidity of about $50 \%$.

This exclusion may also explain the lower (32.9\%) than the literature average (40\%) cross-sectional prevalence of depression after traumatic events among children with PTSD.

Some of the past cross-sectional studies that demonstrated a higher rate of comorbidity (Tang et al., 2018) were made several years after direct traumatization. Since the prospective study of children earthquake survivors estimated that the stability of PTSD tended to decrease across time, while depressive symptoms increased (Cheng et al., 2018), the relatively brief duration of time since war-related trauma may be another reason for the lower cross-sectional prevalence of depression after traumatic events among children with PTSD.

Before the analysis, we did not find any significant differences among adolescents with and without PTSD in their gender distribution, age, number of war-related traumatic events, and time since trauma. We did find that both groups of adolescents were highly exposed to the multiple post-displacement traumatic events, and exhibited high levels of school nonattending - both consistent with other studies of children exposed to war-related trauma (Joshi et al., 2015).

Children in both PTSD and non-PTSD groups had a significant difference in baseline depression severity. It is possible that such a difference may be the result of non-specific PTSD symptoms (mood lability, irritability, sleeping problems) common for both PTSD and MDD (Post et al., 2011; Gros et al., 2012). As a result of this symptom overlap, the children with PTSD had higher baseline depression scores on CDRS-R compared to the children without PTSD. Another important possibility is that some of the children who developed PTSD were already in the process of developing clinical depression.

In our study, depression was more prevalent among girls, consistent with the role of female gender as a significant risk factor for development of depression in traumatized adolescents. These finding were consistent with other studies in traumatized youth (Valdez et al., 2014; Adams et al., 2015) and in the general population (Salk et al. 2017). However, in a subsample of adolescents with PTSD, female gender was nonsignificant.

Post-hoc analysis confirmed the significant effect of PTSD as a risk factor for development of depression. Different theories have been proposed to explain the interaction between PTSD and MDD, including a common genetic mechanism of development and shared risk loci, among others (Smoller, 2016; Duncan et al., 2018).

Another possible model of interaction of PTSD and MDD involves a demoralization mechanism as a response to chronic medical conditions (Mangelli et al., 2005). While most of the children demonstrate improvement in PTSD symptoms with time (Punamaki et al., 2014), those with poor recovery demonstrate stable severity of depressive symptoms (Lai et al., 2013).

We estimated that more than a third of the sample was exposed to significant traumatic life events after displacement, such as bullying, loss of social status, parent's divorce, and so on. Despite the lack of significance of the number of secondary traumatic events with respect to subsequent depression in the full sample, a separate regression analysis in the PTSD cohort of adolescents revealed that secondary traumatic events were a significant risk factor for development of depression.

If meaningful, this finding would be consistent with a 'double-hit hypothesis', namely that adolescents who are more vulnerable to developing PTSD are also susceptible to the dose effect of the number of secondary traumatic events, while adolescents who do not develop PTSD are also less vulnerable to developing MDD.

In addition, these findings may reflect an indirect effect of PTSD-related changes in the coping style strategies and cognitive appraisal (Ehlers et al., 2003; Pfefferbaum et al., 2014; Smith et al., 2013) that can lead to both catastrophizing of routine stimuli and chronicity of the stress reactions (Trickey et al., 2012; Greca et al., 2013; Punamäki et al., 2015).

We did not include baseline CDRS-R scores in the final logistic model due to a high correlation between PTSD variable and CDRS-R (T0) scores that we contributed to an overlap between non-specific PTSD and depressive symptoms.

Two factors were estimated to be protective. TF-CBT is a highly effective form of treatment of adolescent PTSD that also has evidence for decreasing the severity of co-occurring depression (Lenz et al., 2015). In our study, TF-CBT appeared to decrease the risk of development of depression that may result from improvement in PTSD severity (Lai et al., 2012).

Social support in general and peer support specifically are vital for well-being of adolescents and can both alleviate PTSD 
symptoms and serve as a protective factor against depression (van Harmelen et al., 2016; Reavell et al., 2017). School nonattending on a permanent basis was associated with increased risk for development of depression in our study. This finding could be partially related to decreased social and peer support.

Another possible explanation may be that school non-attending is a confounding variable that represents a marker of increased impairment due to PTSD and depression.

Whatever the explanation, this study's findings regarding key role of schools provides strong support for increased resource allocation to enhance school peer and teacher engagement programs as part of early identification and treatment interventions.

In our study, we found that PTSD severity in adolescents with war trauma had declined over time, while depression severity increased, particularly among children with poor recovery. This was consistent with some of the previous findings. The study by Lai and colleagues found a stability of depressive symptoms among children that demonstrated a trajectory of poor recovery from PTSD (Lai et al., 2013). Even though that study did not demonstrate increased depression over time, some of the possible explanations include initially low severity of posttraumatic symptoms and a much younger age of the sample.

In a study of earthquake survivors, Cheng with colleagues found the opposite results - namely that depressive and posttraumatic symptoms had a mutual affect in early period; however, they found in the later periods that depressive symptoms predicted the stability of PTSD. This difference can be a result of the different methodological approaches in our studies, particularly the exclusion criteria and sample features. Cheng and colleagues did not exclude possible pre-exposure mental health disorders. Thus, unlike our study, Cheng and colleagues involved children who had comorbid depression and PTSD at the moment of study enrolment.

This study has a number of limitations. The sample size was medium and limited to a relatively demographically homogenous population of 15-17 year old adolescents. Therefore, results may not generalize to traumatized younger children with other demographic characteristics.

Even though DSM-5 criteria were already available, we applied the DSM-4-TR criteria that corresponded to the routine clinical/research practice and to the available instruments in Ukraine at the moment of the study. This makes comparison of our results to studies using DSM-5 more difficult.
Secondly, PTSD and depression severity was assessed using only data obtained from the adolescent.

Thirdly, all adolescents were recruited through social service agencies; due to the distrust in public services, a significant part of the population did not apply for social assistance. On the other hand, majority of children with PTSD who were recruited into the study had moderate to severe severity of PTSD since those with less severe symptoms did not apply for medical or psychological assistance.

Another limitation was the validation of instruments used in the study. Even though CAPS-CA was translated and backtranslated, and K-SADS-PL and CDRS-R were commonly used in clinical trials and routine practice, no studies on their validation or psychometric properties in Ukrainian had been conducted to date. We also significantly modified the existing version of TESI-C to meet our needs without subsequent validation. We aimed to decrease the possible chance of diagnostic error by using several assessment instruments, including DSM-4-TR criteria.

It was not uncommon for displaced adolescents to spend most of their time in war-affected regions, while coming to nonoccupied territory only for social and financial assistance and hiding this fact due to the fear of possible loss of assistance and financial payments from the government. Between assessments, adolescents were not observed by a research team, so we cannot exclude that some of these adolescents were traumatized by the ongoing war during the study.

Another limitation was that we were not searching for other mental disorders except PTSD and depression during the T0 to T2 period of observation. Despite the fact that no adolescents received medical assistance due to any other reasons except for depression and PTSD in the community, it was possible that episodes of hypomania or mild forms of anxiety disorders were not detected.

Despite the fact that we did not check for the possible presence of learning or intellectual disability, all children were considered to have normal intelligence due to attendance of regular local schools. However, we could not rule out possible mild intellectual disability and possible learning difficulties that could increase the risk of depression.

We were not able to obtain medical charts of all adolescents from the occupied territories, so our data on the absence of previous mental health disorders was often based on the information received from the adolescents and their parents. 
The results of this study need to be considered carefully through the family context. We did not assess the childparent attachment. Secure attachment is especially important in the development of trauma and depression resilience, as demonstrated by the studies of foster children (Sapienza et al., 2011; Suzuki et al., 2015). Besides the fact that war exposure is extremely traumatizing for children, it may affect their parents' mental health too (Charlson et al., 2019). Parental psychopathology mediates the amount of perceived social support and even itself becomes a risk factor for child internalizing disorders (Lester et al., 2010; Zalta et al., 2018). A study of refugees in Australia estimated that caregiver's PTSD was associated with higher levels of child conduct problems, hyperactivity, emotional symptoms, and peer problems (Bryant et al., 2018). Future studies will need to address this limitation as well as address importance of religion and other potential contributors to trauma and depression resilience.

This study's findings make important contributions to our understanding of the interactions among war-related traumatic stress, PTSD symptoms, and depression. However, the role of PTSD as a moderator of depression merits further investigation in larger scale longitudinal studies in diverse populations.

While adolescents with war-related PTSD are at high risk for development of depression, many countries, especially those with low resources, have been unable to provide the children in need with robust and evidence-based mental health services, including TF-CBT. It is vital to develop such capacity, to support children in their access to schools, and to build enhanced social supports to more effectively deal with post-displacement traumatic life events.

\section{ACKNOWLEDGEMENTS}

We would like to thank Ivan Vyshnyvetskyy for his advice regarding the design of the study, Yael Dvir, Steven Hodge, Wynne Morgan, Christopher Bellonci, Richard Styles and Boris Lorberg for valuable suggestions on editing and revision of the paper.

\section{AUTHORS CONTRIBUTION}

$\mathrm{DM}$ and $\mathrm{ON}$ designed the study. DM, ON and IM supervised patient recruitment. DM and $\mathrm{ON}$ undertook data management. DM and IM undertook statistical analyses. DM and IM wrote the first draft of themanuscript. ON critically reviewed the manuscript. All authors contributed to and have approved the final manuscript.

\section{CONFLICT OF INTEREST}

The authors declare that they have no conflict of interests.

\section{ETHICAL APPROVAL}

This study was approved by Committee of Ethics in Bogomolets National Medical University. All procedures were in accordance with the ethical standards of the institutional and national research committee and with the 1964 Helsinki declaration and its later amendments or comparable ethical standards.

\section{FUNDING}

This study is part of a Ph.D. Dissertation Thesis conducted in Bogomolets National Medical University. No financial support was received to conduct the study.

\section{INFORMED CONSENT}

Informed consent was received from child and both of caregivers before the study enrollment.

\section{REFERENCES}

Adams, Z. W., Danielson, C. K., Sumner, J. A., McCauley, J. L., Cohen, J. R., \& Ruggiero, K. J. (2015). Comorbidity of PTSD, Major Depression, and Substance Use Disorder Among Adolescent Victims of the Spring 2011 Tornadoes in Alabama and Joplin, Missouri. Psychiatry, 78(2), 170-185. https://doi.org/10.1080/003 32747.2015.1051448
American Psychiatric Association. (2000). Diagnostic and statistical manual of mental disorders: DSM-IV-TR. Washington, DC: Author.

Ayazi, T., Lien, L., Eide, A. H., Ruom, M. M., \& Hauff, E. (2012). What are the risk factors for the comorbidity of posttraumatic stress disorder and depression in a war-affected population? A cross- 
sectional community study in South Sudan. BMC Psychiatry. https://doi.org/10.1186/1471-244X-12-175

Banks, D. M., \& Weems, C. F. (2014). Family and peer social support and their links to psychological distress among hurricane-exposed minority youth. American Journal of Orthopsychiatry. https://doi. org/10.1037/ort0000006

Blake, D. D., Weathers, F. W., Nagy, L. M., Kaloupek, D. G., Gusman, F. D., Charney, D. S., \& Keane, T. M. (1995). The development of a Clinician-Administered PTSD Scale. Journal of Traumatic Stress. https://doi.org/10.1007/BF02105408

Bryant, R. A., Edwards, B., Creamer, M., O'Donnell, M., Forbes, D., Felmingham, K. L., ... \& Van Hooff, M. (2018). The effect of post-traumatic stress disorder on refugees' parenting and their children's mental health: a cohort study. The Lancet Public Health, 3(5), e249-e258.

Cénat, J. M., \& Derivois, D. (2015). Long-term outcomes among child and adolescent survivors of the 2010 Haitian earthquake. Depression and Anxiety. https://doi.org/10.1002/da.22275

Charlson, F., van Ommeren, M., Flaxman, A., Cornett, J., Whiteford, H., \& Saxena, S. (2019). New WHO prevalence estimates of mental disorders in conflict settings: a systematic review and meta-analysis. The Lancet. https://doi.org/10.1016/S01406736(19)30934-1

Cheng, J., Liang, Y., Fu, L., \& Liu, Z. (2018). Posttraumatic stress and depressive symptoms in children after the Wenchuan earthquake. European Journal of Psychotraumatology, 9(sup2), 1472992. https://doi.org/10.1080/20008198.2018.1472992

Duncan, L., Ratanatharathorn, A., Aiello, A. et al. Largest GWAS of PTSD ( $N=20070$ ) yields genetic overlap with schizophrenia and sex differences in heritability. Mol Psychiatry 23, 666-673 (2018) doi: $10.1038 / \mathrm{mp} .2017 .77$

Fazel, M., Reed, R. V., Panter-Brick, C., \& Stein, A. (2012). Mental health of displaced and refugee children resettled in high-income countries: Risk and protective factors. The Lancet. https://doi. org/10.1016/S0140-6736(11)60051-2

Geltman, P. L., Grant-Knight, W., Mehta, S. D., Lloyd-Travaglini, C., Lustig, S., Landgraf, J. M., \& Wise, P. H. (2005). The “Lost Boys of Sudan": Functional and behavioral health of unaccompanied refugee minors resettled in the United States. Archives of Pediatrics and Adolescent Medicine. https://doi.org/10.1001/ archpedi.159.6.585
Goldbeck, L., Muche, R., Sachser, C., Tutus, D., \& Rosner, R. (2016). Effectiveness of Trauma-Focused Cognitive Behavioral Therapy for Children and Adolescents: A Randomized Controlled Trial in Eight German Mental Health Clinics. Psychotherapy and Psychosomatics. https://doi.org/10.1159/000442824

Gros, D. F., Price, M., Magruder, K. M., \& Frueh, B. C. (2012). Symptom overlap in posttraumatic stress disorder and major depression. Psychiatry Research. https://doi.org/10.1016/j. psychres.2011.10.022

Jensen, T. K., Holt, T., \& Ormhaug, S. M. (2017). A Follow-Up Study from a Multisite, Randomized Controlled Trial for Traumatized Children Receiving TF-CBT. Journal of Abnormal Child Psychology, 1-11. https://doi.org/10.1007/s10802-017-0270-0

Joshi, P. T., \& Fayyad, J. A. (2015). Displaced Children: The psychological implications. Child and Adolescent Psychiatric Clinics of North America, 24(4), 715-730.

Kar, N., \& Bastia, B. K. (2006). Post-traumatic stress disorder, depression and generalised anxiety disorder in adolescents after a natural disaster: A study of comorbidity. Clinical Practice and Epidemiology in Mental Health. https://doi.org/10.1186/17450179-2-17

Karam, E. G., Mneimneh, Z. N., Dimassi, H., Fayyad, J. A., Karam, A. N., Nasser, S. C., ... Kessler, R. C. (2008). Lifetime prevalence of mental disorders in Lebanon: First onset, treatment, and exposure to war. PLoS Medicine. https://doi.org/10.1371/journal. pmed.0050061

Kaufman, J., Birmaher, B., Brent, D., Rao, U., Flynn, C., Moreci, P., ... Ryan, N. (1997). Schedule for affective disorders and schizophrenia for school-age children-present and lifetime version (K-SADS-PL): Initial reliability and validity data. Journal of the American Academy of Child and Adolescent Psychiatry. https://doi.org/10.1097/00004583-199707000-00021

Kien, C., Sommer, I., Faustmann, A., Gibson, L., Schneider, M., Krczal, E., ... Gartlehner, G. (2019). Prevalence of mental disorders in young refugees and asylum seekers in European Countries: a systematic review. European Child and Adolescent Psychiatry. https://doi.org/10.1007/s00787-018-1215-z

Lai, B. S., La Greca, A. M., Auslander, B. A., \& Short, M. B. (2013). Children's symptoms of posttraumatic stress and depression after a natural disaster: Comorbidity and risk factors. Journal of Affective Disorders, 146(1), 71-78. https://doi.org/10.1016/j. jad.2012.08.041 
Lenz, A. S., \& Hollenbaugh, K. M. (2015). Meta-analysis of trauma- focused cognitive behavioral therapy for treating PTSD and co- occurring depression among children and adolescents. Counseling Outcome Research and Evaluation, 6,18-32.

Lester, P., Peterson, K., Reeves, J., Knauss, L., Glover, D., Mogil, C., Duan, N., Saltzman, W., Pynoos, R., Wilt, K., \& Beardslee, W. (2010). The long war and parental combat deployment: Effects on military children and at-home spouses. Journal of the American Academy of Child \& Adolescent Psychiatry, 49(4), 310-320. https:// doi.org/10.1097/00004583-201004000-00006

Mannarino, A. P., Cohen, J. A., Deblinger, E., Runyon, M. K., \& Steer, R. A. (2012). Trauma-Focused Cognitive-Behavioral Therapy for Children: Sustained Impact of Treatment 6 and 12 Months Later. Child Maltreatment. https://doi.org/10.1177/1077559512451787

Mangelli, L., Fava, G. A., Grandi, S., Grassi, L., Ottolini, F., Porcelli, P., ... Sonino, N. (2005). Assessing demoralization and depression in the setting of medical disease. Journal of Clinical Psychiatry. https://doi.org/10.4088/JCP.v66n0317

McLean, C. P., Morris, S. H., Conklin, P., Jayawickreme, N., \& Foa, E. B. (2014). Trauma Characteristics and Posttraumatic Stress Disorder among Adolescent Survivors of Childhood Sexual Abuse. Journal of Family Violence. https://doi.org/10.1007/s10896-014-9613-6

Myles, P., Swenshon, S., Haase, K., Szeles, T., Jung, C., Jacobi, F., \& Rath, B. (2018). A comparative analysis of psychological trauma experienced by children and young adults in two scenarios: evacuation after a natural disaster vs forced migration to escape armed conflict. Public Health. https://doi.org/10.1016/j. puhe.2018.03.012

Nader, K. O., Kriegler, J. A., Blake, D. D., Pynoos, R. S., Newman, E., \& Weather, F. W. (1996). Clinician Administered PTSD Scale, Child and Adolescent Version. White River Junction, VT: National Center for PTSD.

Nanni, V., Uher, R., \& Danese, A. (2012). Childhood maltreatment predicts unfavorable course of illness and treatment outcome in depression: A meta-analysis. American Journal of Psychiatry. https://doi.org/10.1176/appi.ajp.2011.11020335

Pejuskovic, B., Lecic-Tosevski, D., \& Toskovic, O. (2020). Longitudinal study of PTSD and depression in a war-exposed sample - comorbidity increases distress and suicide risk. Global Psychiatry. https://doi.org/10.2478/gp-2020-0004

Perkins, J. D., Ajeeb, M., Fadel, L., \& Saleh, G. (2018). Mental health in Syrian children with a focus on post-traumatic stress: a cross- sectional study from Syrian schools. Social Psychiatry and Psychiatric Epidemiology. https://doi.org/10.1007/s00127-018-1573-3

Post, L. M., Zoellner, L. A., Youngstrom, E., \& Feeny, N. C. (2011). Understanding the relationship between co-occurring PTSD and MDD: Symptom severity and affect. Journal of Anxiety Disorders. https://doi.org/10.1016/j.janxdis.2011.08.003

Poznanski, E. O., \& Mokros, H. B. (1996). Children's depression rating scale, revised (CDRS-R). Los Angeles: Western Psychological Services.

Priebe, S., Matanov, A., Janković Gavrilović, J., McCrone, P., Ljubotina, D., Knežević, G., ... Schützwohl, M. (2009). Consequences of Untreated Posttraumatic Stress Disorder Following War in Former Yugoslavia: Morbidity, Subjective Quality of Life, and Care Costs. Croatian Medical Journal. https://doi.org/10.3325/ cmj.2009.50.465

Punamaki, R. L., Palosaari, E., Diab, M., Peltonen, K., \& Qouta, S. R. (2014). Trajectories of posttraumatic stress symptoms (PTSS) after major war among Palestinian children: Trauma, family- and child-related predictors. Journal of Affective Disorders, 172, 133140. https://doi.org/10.1016/j.jad.2014.09.021

Ramsawh, H. J., Fullerton, C. S., Mash, H. B. H., Ng, T. H. H., Kessler, R. C., Stein, M. B., \& Ursano, R. J. (2014). Risk for suicidal behaviors associated with PTSD, depression, and their comorbidity in the US Army. Journal of Affective Disorders, 161, 116-122.

Razumkov Center in collaboration with the All-Ukrainian Council of Churches (2016). Religion, Church, Society and State: Two Years after Maidan. Retrieved from http://old.razumkov.org.ua/upload/ Religiya_200516_A4.compressed.pdf

Reavell, J., \& Fazil, Q. (2017). The epidemiology of PTSD and depression in refugee minors who have resettled in developed countries. Journal of Mental Health. https://doi.org/10.1080/0963 8237.2016 .1222065

Ribbe, D. (1996). Psychometric review of traumatic event screening instrument for children (TESI-C). Measurement of Stress, Trauma, and Adaptation.

Salk, R. H., Hyde, J. S., \& Abramson, L. Y. (2017). Gender differences in depression in representative national samples: Meta-analyses of diagnoses and symptoms. Psychological Bulletin. https://doi. org/10.1037/bul0000102

Salloum, A., Johnco, C., Smyth, K. M., Murphy, T. K., \& Storch, E. A. (2018). Co-Occurring Posttraumatic Stress Disorder and 
Depression Among Young Children. Child Psychiatry and Human Development, 49(3), 452-459. https://doi.org/10.1007/s10578017-0764-6

Sapienza, J. K., \& Masten, A. S. (2011). Understanding and promoting resilience in children and youth. Current Opinion in Psychiatry. https://doi.org/10.1097/YC0.0b013e32834776a8

Smoller, J. W. (2016). The Genetics of Stress-Related Disorders: PTSD, Depression, and Anxiety Disorders. Neuropsychopharmacology. https://doi.org/10.1038/npp.2015.266

Suzuki, H., \& Tomoda, A. (2015). Roles of attachment and selfesteem: Impact of early life stress on depressive symptoms among Japanese institutionalized children. BMC Psychiatry. https://doi. org/10.1186/s12888-015-0385-1

Tang, B., Liu, X., Liu, Y., Xue, C., \& Zhang, L. (2014). A metaanalysis of risk factors for depression in adults and children after natural disasters. BMC Public Health, 14(1), 623. https://doi. org/10.1186/1471-2458-14-623

Thabet, A. A. M., Abed, Y., \& Vostanis, P. (2004). Comorbidity of PTSD and depression among refugee children during war conflict. Journal of Child Psychology and Psychiatry and Allied Disciplines. https://doi.org/10.1111/j.1469-7610.2004.00243.x

Tural, Ü., Önder, E., \& Aker, T. (2012). Effect of depression on recovery from PTSD. Community Mental Health Journal. https:// doi.org/10.1007/s10597-010-9359-4

United Nations General Assembly (2018). Report on the human rights situation in Ukraine (16 May to 15 August 2018). Retrieved from www.ohchr.org/Documents/Countries/UA/ ReportUkraineMay-August2018_EN.pdf.

Valdez, C. E., Bailey, B. E., Santuzzi, A. M., \& Lilly, M. M. (2014). Trajectories of Depressive Symptoms in Foster Youth Transitioning Into Adulthood: The Roles of Emotion Dysregulation and PTSD. Child Maltreatment, 19, 209-218. https://doi. org/10.1177/1077559514551945

van Harmelen, A. L., Gibson, J. L., St Clair, M. C., Owens, M., Brodbeck, J., Dunn, V., ... Goodyer, I. M. (2016). Friendships and Family Support Reduce Subsequent Depressive Symptoms in At-Risk Adolescents. PloS One. https://doi.org/10.1371/journal. pone. 0153715
Völkl-Kernstock, S., Karnik, N., Mitterer-Asadi, M., Granditsch, E., Steiner, H., Friedrich, M. H., \& Huemer, J. (2014). Responses to conflict, family loss and flight: Posttraumatic stress disorder among unaccompanied refugee minors from Africa. Neuropsychiatrie. https://doi.org/10.1007/s40211-013-0094-2

Zalta, A. K., Bui, E., Karnik, N. S., Held, P., Laifer, L. M., Sager, J. C., ... Ohye, B. (2018). Examining the Relationship Between Parent and Child Psychopathology in Treatment-Seeking Veterans. Child Psychiatry and Human Development. https://doi.org/10.1007/ s10578-017-0743-y

Zukerman, G., \& Korn, L. (2014). Post-Traumatic Stress and World Assumptions: The Effects of Religious Coping. Journal of Religion and Health. https://doi.org/10.1007/s10943-013-9755-5 